\title{
Temporal Experience and the A versus B debate
}

(in the Routledge Handbook of Philosophy of Temporal Experience, ed. by Ian Phillips)

This chapter discusses some aspects of the relation between temporal experience and the A versus B debate. To begin with, I provide an overview of the A versus B debate and, following Baron et al. (2015), distinguish between two B-theoretic responses to the Atheoretic argument from experience, veridicalism and illusionism. I then argue for veridicalism over illusionism, by examining our (putative) experiences as of presentness and as of time passing. I close with some remarks on the relation between veridicalism and a deflationary view of the A versus B debate. I suggest that the deflationary view can provide further support for veridicalism.

\section{Introduction}

The metaphysics of time has been characterised by the opposition between the A-theory and the B-theory (or block universe view).

The B-theory has two components. First, all times and/or events exist. And second, there is a complete tenseless description of temporal reality. A tenseless description is one that stays accurate, because it mentions only such things as which events happen when and how they are temporally related to one another. So it mentions only tenseless facts about B-relations like simultaneity and succession, not tensed facts like that it's 12:27.

It's an interesting question exactly how to understand 'complete', but this is beyond the scope of this chapter. It's likely that the notion of completeness in play will make reference to something like fundamentality or joint-carving. So let's think of the second 
component of the B-theory as the claim that there is a tenseless description of temporal reality that is more fundamental than any tensed description.

Why might one disagree with the B-theory? One prominent motivation is the conviction that time passes. In John Norton's words: 'Time passes. Nothing fancy is meant by that. It is just the mundane fact known to us all that future events will become present and then drift off into the past.' (2010, p. 24) Time's passing seems to involve the transfer of some kind of metaphysical privilege from one time to another. Hence it requires that one time be metaphysically privileged, as captured in a (fundamental) tensed fact like that it's $12: 27$.

The metaphysical privilege consists in different things according to different versions of the A-theory. It might be being the only time that exists (presentism), being the latest time that exists (growing block view), being the time at which possibilities are actualized (dynamic branching views), or simply being the one time that is present in an absolute, non-perspectival sense (moving spotlight view). 'Non-perspectival' means not just relative to itself (even B-theorists allow that each time is present in that sense, like each spatial location is here relative to itself), but in an absolute, non-time-relative sense.

So we seem to have a debate about whether time passes (or whether, fundamentally, time passes). However, lately some have asked why B-theorists should feel pressured to uphold something as outlandish as the claim that time doesn't pass. Why shouldn't they instead say that time's passing just consists in there being a succession of times? ${ }^{1}$ Let's call this the tenseless passage move. I'll suggest in the final section that this move can be motivated by a substantial thesis, namely a deflationary view of the debate. But for now what matters is the stock reply (see Skow 2015, p. 2). Sure, we'll give you the label 
'passage'. But the kind of passage the B-theory includes is anemic (i.e. bloodless, lifeless, not the real thing). The debate is about whether there is passage of a robust kind. That's the kind that requires metaphysical privilege to be transferred from time to time. The Btheory excludes that. (As mentioned, I re-consider the tenseless passage move in the final section.)

As a final preliminary, note that all these views make use of notions like 'times', which are out of place in relativistic physics. That can seem odd, especially if one thinks that much of the interest in this debate ultimately derives from its relation to modern physics. But the B-theory can be straightforwardly adapted to a relativistic context. Its first component, for example, becomes the view that all spatiotemporal regions exist, independently of their extent in spatial, null, and temporal directions. A-theoretic views, on the other hand, are notoriously hard to reconcile with relativity. Insofar as they rely on a metaphysically privileged global present, they require structure that is conspicuously absent from Minkowski spacetime, the spacetime of special relativity. ${ }^{2}$ For that reason, what follows can be seen as one aspect of the broader project of relating the findings of modern physics to everyday experience.

\section{The argument from experience}

A-theorists have long pointed to the nature of experience in support of their view. Nowadays, they often offer the following inference to the best explanation (Baron et al. 2015):

(1) We have experiences as of time (robustly) passing. ${ }^{3}$ 
(2) If we have experiences as of time (robustly) passing, then any reasonable explanation of this relies on the (robust) passage of time being an objective feature of reality.

(3) Hence, the (robust) passage of time is an objective feature of reality.

The thought is that if A-theorists provide the only explanation of our experiences as of time (robustly) passing, then a fortiori they provide the best such explanation. Suppose one accepts the assumption that A-theorists can provide a reasonable passage-based explanation of these putative experiences. What should be said about the argument?

Let's call those B-theorists who reject (1) veridicalists. ${ }^{4}$ The most salient B-theoretic alternative to veridicalism, and the position that is presented by Baron et al. (2015) as the most widespread among B-theorists, is illusionism. Illusionists accept (1), but reject (2), because they think that there are reasonable explanations of our experiences as of time (robustly) passing that don't rely on there being (robust) passage.

(Illusionism may be less widespread than Baron et al. present it as being. For example, they classify Hugh Mellor (1998), Huw Price (1996) and Craig Callender (2008) as illusionists. But as we'll see, Mellor argues against the claim that we perceive Aproperties. Similarly, Callender (2008) argues against the claim that there is an “'experience of the present' as contemporary metaphysicians conceive it" (p. 2). Moreover, arguably, there are both illusionist and veridicalist interpretations of Price (1996, pp. 14-15).)

I'll offer support for veridicalism over illusionism. That is, I'll argue against premise (1). I'll sometimes speak loosely and say I'm defending veridicalism, but without a defense of the B-theory, it's only a conditional defense of veridicalism. Moreover, since A-theorists can in principle also reject (1), it's a defense of a position about temporal experience 
(namely the negation of (1)) that is compatible with the A-theory, though rarely combined with it.

The first thing to ask about the argument is what is meant by 'experience' here. Let's distinguish between two things that could be meant. The distinction is well illustrated by the following quotation from Robin Le Poidevin:

"We are indirectly aware of the passage of time when we reflect on our memories, which present the world as it was, and so a contrast with how things are now. But much more immediate than this is seeing the second hand move around the clock, or hearing a succession of notes in a piece of music, or feeling a raindrop run down your neck. There is nothing inferential, it seems, about the perception of change and motion: it is simply given in experience.” $(2007$, p. 87$)$

It's this latter direct, perceptual awareness I take the argument to be about (and that I'll take 'experience' to denote). But it will also be useful to have a term for the first, more indirect kind of awareness. Let's call it temporal EXPERIENCE.

The term "temporal experience" in the first sense, i.e. in the sense of time perception, can seem a little puzzling. Time is not an ordinary object, so we don't perceive it in the way that we perceive ordinary objects. But we do seem to perceive temporal features of events (or so I'll assume here). For example, we perceive things happening after one another.

Now, both the veridicalist and the illusionist can allow this. They can agree that we perceive succession, simultaneity, and duration. But the illusionist is likely to think we only perceive those things because we perceive (robust) passage, or by perceiving (robust) passage. In seeing a movement, you see the object's being in one place at one time and in another place at another time. But you only see this by seeing the object's 
being in one place becoming present and then past, while the object's being in another place becomes present. You have an experience as of a change that involves (robust) passage. Some illusionists call this "animated" or "flowing change".

\section{A sense of presentness?}

If we have experiences as of time (robustly) passing, then presumably we have experiences as of metaphysical privilege. Do we?

We certainly have a temporally limited perceptual horizon. Most of the time we perceive events that are roughly simultaneous with our perceptions (Le Poidevin 2007, pp. 85-86). We don't perceive the future because perception is a causal process, and causes, typically at least, precede their effects. And we mostly don't perceive the distant past because there is no action at a spatial and temporal distance. Events can't directly cause perceptual states in us - they must do so via a series of intermediate causes. Moreover, in most circumstances, signals degrade with spatial and temporal distance, so they only reach us if our spatial separation from them is not too large (the obvious exception being the night sky).

Hugh Mellor argues against the claim that we perceive (non-perspectival) presentness by pointing out that when one learns that some celestial event occurred long ago, its perceptible appearance does not change. Hence, events don't look present (1998, p. 16). Unfortunately for the veridicalist, this doesn't follow. Indeed, the phenomenon in question might be taken to show that this feature of perception is conspicuously resilient and independent of our tensed beliefs about the event's occurrence. 
What we should keep in mind, though, is that the veridicalist can allow that we perceive events and indeed that we perceive them as happening presently in a perspectival sense. The question is just whether we also perceive events as happening presently in the absolute, non-perspectival sense.

Uriah Kriegel speaks of a felt temporal orientation here: in perceiving rain one perceives it as present, just like in episodically remembering rain one remembers it as past (2015). The veridicalist can say two things about this. The first is that what Kriegel describes as a felt temporal orientation, even if it exists, may simply be due to our present-tensed beliefs that things are happening. It may simply be that while perceiving the rain, we also believe it to be present. And of course, these beliefs can be true. B-theorists needn't deny that tensed beliefs can be true if had at the right times, nor that they are essential for timely action. (And even if there are further unsolved problems about indexicality, these are not specific to time.)

The second thing to say is that even if there is a felt temporal orientation over and above this, the veridicalist may be able to accommodate it using Kriegel's own suggestion. Kriegel says that we needn't think of felt temporal orientation as part of what is perceived, i.e. of perceptual contents. Instead we can think of it as a matter of how we perceive. Call this the attitudinal view.

He finds this idea in Brentano, and argues that it describes quite a widespread phenomenon in our mental life. For example, in fearing a snake, there is a sense in which we experience it as dangerous. But what we fear isn't that the snake is dangerous - it's just the snake. The danger is part of the very attitude of fearing, not of its content; it's not attributed to the snake. Similarly, in perceiving, we don't attribute presentness to things 
in the world, we don't perceive things-as-present. Rather, we perceive-as-present the things in the world.

Admittedly, further questions could be raised about this distinction, and it remains to be seen how promising the attitudinal view is. The point is just that if there is felt temporal orientation over and above present-tensed beliefs, and if this is how to think of it, then it actually fits well into the veridicalist's story. ${ }^{5}$

There is another argument from experience in the vicinity. According to this argument, we don't have experiences as of presentness, nor a feeling of presentness more easily explicable by A-theorists. But experience nonetheless supports the A-theory, because it singles out the present in another way: only one time's experiences are presented to one, or are available to one, or are occurring simpliciter (Balashov 2005, Skow 2015). There is a lack of parity between one's experiences from different times. Callender has articulated understandable dissatisfaction with such claims: "what is occurring simpliciter? The answer is more Latin - the experience, [Balashov] says, is "sui generis" - but we never get more lumen" (2008, p. 6). And even Skow, one of the two proponents of the argument, concedes that denying the intelligibility of the notion may be a reasonable Btheoretic response (2015, p. 221).

Suppose the veridicalist is right that we don't have experiences as of one time's being metaphysical privileged. Why then do we tend to think of the time we're at as metaphysically privileged, and as global? Call this the presentness intuition. Callender suggests that "the strength of such an intuition is evinced by the existence of philosophy of time itself, with so many philosophers arguing for presentism, as well as the reaction 
one finds in students when teaching the relativity of simultaneity. Part of the shock of relativity is its conflict with the idea of a special common now" (2008, p. 7).

Jeremy Butterfield (1984) offers an explanation for something in the vicinity of the presentness intuition. Butterfield considers the typical time scales on which objects around us change their observable properties, and compares these to how long it takes for perceptual signals to reach us and be processed. At least in the case of sight, sound, and touch, we can usually take our perceptual beliefs to be still accurate by the time we form them. This makes sense from the perspective of evolution: it would be a grave disadvantage to take so long to process perceptual signals that one's perceptual beliefs were typically no longer accurate by the time we formed them.

What does this show? Butterfield takes it to explain why observation reports, i.e. perceptual judgments or beliefs tend to have a temporally local but spatially dispersed subject matter. Presumably the facts about our perceptual horizon rehearsed above are in the background here. The point is that what our senses typically inform us about is the time at which they inform us, rather than some earlier time. So we can proceed as if our perceptual horizon was even more temporally narrow than it is. But we can't proceed as if it's spatially narrow, because it's not. And, says Butterfield, the fact that perceptual judgments typically have this temporally but not spatially limited subject matter means that it's useful to recognize a present-tensed but not a spatially-tensed sense of existence. That's close to the explanandum constituted by the presentness intuition. And the explanation carries over.

Butterfield also points to the related fact that verbal communication or communication by signing is usually such that the time-lags involved are negligible. We can usually take the 
tensed reports we give to each other to be accurate when we receive them, but we can't do the same with reports that incorporate a spatial perspective. "[E]ach person can usually take a token of 'now' which they hear to refer to the time of reception, as well as the time of utterance, without misinterpreting the speaker, [when] they cannot analogously take a token of 'here' to refer to where they themselves are." (p. 173).

Inter-subjective agreement on what's happening now reinforces the impression of objectivity. It gives us the sense of sharing a common now, and this in turn encourages the tendency to think that the now is metaphysically significant.

\section{A sense of passage?}

If the veridicalist is right, then we don't have experiences as of time (robustly) passing. Hearing a printer hum, seeing a movement, noticing that five minutes have passed - none of these involve perceiving something's being first present and then past.

That can seem hard to believe. One way to see that it's nonetheless plausible is to take a closer look at typical illusionist explanations. Recall that the illusionist wants to offer a reasonable (robust) passage-free explanation for how the brain creates these experiences in a B-theoretic, (robust) passage-free world. Their explanations have often been based on experimental results from cognitive science concerning certain kinds of perceptual illusions.

For example, according to Laurie Paul, both veridical perception of change and illusory perception of change involve an illusion of (robust) passage (2010). They're both experiences as of animated, or flowing change. So the latter is doubly illusory, the former only singly so. And now the idea is that B-theorists can take the explanation appropriate 
to cases of illusory motion perception and apply it, with very few changes, to the pervasive illusion of passage. The key is to think of the static images involved in perceptual illusions, or of films or flipbooks, as analogous to the B-theorist's static tenseless facts underlying change.

Take for example the 'colour phi' experiment, in which a subject is presented with a rapid succession of flashes of a static dot of different colours on opposite sides of a screen. If the flashes are timed and spaced appropriately, the subject can have an illusion of a dot moving back and forth, and abruptly changing its colour somewhere along the trajectory. Now think of the static inputs [red flash left], [green flash right] as analogous to the static B-theoretic facts underlying any change, such as [O has property $\mathrm{P} 1$ at $\mathrm{t} 1$ ], [O has property $\mathrm{P} 2$ at $\mathrm{t} 2$ ]. In both cases, the brain "responds to closely spaced inputs that have sufficient similarity (yet have qualitative contrasts of some sort) by accommodating and organizing the inputs", thereby creating a sense of animated change (p. 22). In a nutshell, the recommendation is: if you're a B-theorist, think of life as a whole as a kind of film. There are only static images, one after the other, but because of our limited powers of discrimination, we experience animation instead.

The problem with this is that the analogy between film and life is strained, even on the Btheory. Whether there is a continuity of times or not is a question that's entirely orthogonal to the A versus B debate. The block universe needn't have any gaps. And even if it did necessarily involve gaps, they wouldn't be gaps in time. That is, there are in the block universe no static inputs for our brain in the way that there are such static images in films, or in the colour-phi experiment. We don't first experience one tenseless fact, O's being $\mathrm{P}$ at t1, and then after a little while, the next tenseless fact, O's being $\mathrm{Q}$ at 
t2. As Christoph Hoerl says, the argument trades on an equivocation in the word 'static'. If there's anything static about the block universe, it's in a very different sense of the word from the one applicable to perceptual illusions (2014a, 2014b).

One might object that the point is that the analogy is close enough. But close enough would here mean, close enough for the empirically well-documented mechanism to shed light on the putative mechanism responsible for the pervasive illusion of (robust) passage. And it's hard to see how it has done that. (I argue for this in more detail in my (2013b).) The important thing to note is that if this is right, it doesn't just pose a problem for this particular way of executing the illusionist's explanatory project. Rather, it throws doubt on the project's starting point. The explanation, as mentioned, trades on an ambiguity in the word 'static'. In order for it to work, there should, on the B-theory, be discreteness, or rather a gappiness of the kind that's found in the colour-phi phenomenon. If there was, the explanation would work. But plausibly, what it would then explain would be an illusion of continuity - of continuous motion and persistence. In a gappy block universe, the mechanism would produce experiences as of non-gappiness. And if that's all that needs explaining, veridicalists are right.

This isn't knock-down: an illusionist could insist that in this gappy block universe, there would then be two separate illusions produced, one of continuous motion, and one of flow, and somehow one mechanism would produce both. But this claim of a second illusion looks contrived in the context of this explanation. Effectively, we've had to misconstrue the B-theory in order to offer an explanation for the alleged experience as of (robust) passage. That should give the illusionist some pause. 
If veridicalism is correct, then as we've seen already for presentness, the question arises as to why it is we tend to think of time in A-theoretic ways. It's a good question exactly who is meant by 'we' here. 'The folk' may not have views, let alone uniform views, about this metaphysical issue. But as Callender's remarks suggest (2008, p. 7), the philosophy of time is some evidence for the following claim: as soon as one reflects on the metaphysics of time and its passing (whether as a metaphysician or not), A-theoretic ideas are likely to surface, and to be felt to have a certain intuitive appeal, even if they are not ultimately endorsed.

One important part of the story is surely the asymmetry in our epistemic access to the past and the future. Eric Olson imagines a similar spatial asymmetry. Think about how things would seem if light waves only propagated towards the north. Everything to the south would appear bright, while everything to the north would appear dark. You'd feel as if you were at the boundary between the dark and bright parts of the Earth, and as if the dawn followed you around: as you moved north, "the darkness would seem to recede, so that more of the earth became bright" $(2009$, p. 446).

I like this thought experiment, but I think it's significant that it involves movement. One way to think of Olson's point would be that we tend to think that time (robustly) passes because, given the epistemic temporal asymmetry, as we move through time, the boundary of our knowledge shifts. That is, given that at each time, we remember only earlier ones, then as we move through time, we (find out and then) remember more. But of course it's precisely this movement through time that's at issue, and so hard to make sense of. On the one hand, we can't move through time, in the way we move through 
space, at least not when we're not time travelling. On the other hand, it's precisely a kind of enforced movement through time, or of time past us, that we're prone to imagining. There seem to be two additional relevant disanalogies between time and space. The first is that time, unlike space, is one-dimensional (Le Poidevin and Mellor 1987). Given that our space-time route is continuous, we can't leave out any time between two others, whilst we can leave out any given spatial location between two others. There is no second temporal dimension to move into. In that sense we have a greater freedom as to which spatial locations to include in our life story than which times to include in it.

The other is that in a causally ordered sequence of pairs of spatial and temporal locations (supposing now that space were one-dimensional too), the temporal coordinate of the elements monotonically increases, but the spatial one need not. This is significant because it helps explain why we feel a certain passivity with respect to time that we don't feel with respect to space (Deng 2013c). Recall the presentness intuition. At each time, that time seems special to the point that we are sometimes inclined to attribute metaphysical significance to it. And we remember all the previous times seeming special in just the same way. So we wonder how this time got to be 'it', and how we got 'taken to' the later time. After all, we didn't take ourselves there. Of course, by looking after ourselves we contribute to our continued existence; but that the later time figures in our life story isn't the result of any of our actions.

However, we can see now that there's nothing mysterious about this. It's just a reflection of the fact that human action is a causal process, and causes (typically) precede their effects. So whatever we decide to attempt or not to attempt, the result will be an aspect of what happens at a later time. 


\section{Re-thinking passage}

A veridicalist could stop here. They could say that the above provides reasons to reject premise (1) in the argument from experience, and an explanation for why we nevertheless sometimes think of time in A-theoretic ways.

Note that on this veridicalist's story, while experience doesn't involve A-theoretic content, EXPERIENCE does. Recall that temporal EXPERIENCE is an indirect kind of temporal awareness that arises when we reflect on how things used to be and compare them to how they are now. One example of this is noticing that the hour-hand of a clock has moved on; another is reflecting on how one has changed over the years. In saying that the content of temporal EXPERIENCE is partly A-theoretic, the veridicalist would be claiming that our indirect awareness of time over longer time scales (than the short time scales most relevant to time perception) is characterised by a tendency towards a false belief in (robust) passage. And prima facie, that seems to be suggested by the previous sections.

So on this veridicalist view, there would be no perceptual illusion involving (robust) passage; but there would be a cognitive illusion, colouring our longer term cognitive and emotional relationship to time. In this final section, I want to sketch a different interpretation and development of the veridicalist's story.

Recall the tenseless passage move mentioned at the beginning. Why not say that time's passing consists in there being a succession of times? The stock reply was to agree to the re-labeling, but insist that that kind of passage is anemic, not robust. The reply re-iterates 
a presupposition of the debate, namely that there are theories of time that better capture its dynamicity than others.

But the tenseless passage move can be motivated by a deflationary view of the debate that rejects this presupposition. On that view, there is less at stake in the debate than meets the eye, because the idea of 'robust passage' is mis-guided. There are no robust theories of time's passing.

One immediate worry is this. How can there be no robust theories of passage? If by that we just mean, theories of robust passage, then aren't these just A-theoretic accounts of passage, of which there clearly are some?

Let's concede that there may be a thin reading of 'robust' on which that's right. On that thin reading, a robust account of passage is just any A-theoretic account according to which time passes. As long as the view attributes metaphysical privilege to one time, for example sole existence, or absolute presentness, and as long as it affirms that time passes, it's a robust account of passage.

This would be an all or nothing sense of 'robustness'. However, there clearly is also a thick sense of 'robustness' on which robustness comes in degrees. And it's the search for robustness in this thick sense that drives the debate. Skow's 'Objective Becoming' (2015) is a representative example. Though not without misgivings, he there embarks on the project of finding out how robust various versions of the A-theory are, i.e. how robust the passage is that they can deliver. For example, he suggests that presentism contains passage that is less robust than that contained in some versions of the moving spotlight view. 
The deflationary view rejects the presupposition that some theories are more robust than others. That is, it declines the use of the term 'robust' (in this thick sense), and with it the use of the term 'anemic'. This can provide motivation for the tenseless passage move. The contention is that succession is as good as it gets, passage-wise.

A defense of this view is beyond the scope of this chapter, but I'll close with a few remarks about its relation to veridicalism. None of the above depends on the deflationary view. But veridicalism is compatible with, and can gain further support from, the deflationary view.

There are two related avenues of support. Note first that it's part of the deflationary view that premise (1) is about robust passage in the thick sense in which robustness comes in degrees - i.e. the sense in which, according to the deflationary view, the search for robust theories is misguided. The disagreement about temporal experience concerns whether or not we perceive robust passage in the sense that someone like Skow is trying to capture. The deflationary view rejects this project, and maintains that robust theories can't ultimately be made sense of. If that is right, then that is all the more reason to deny that we perceive robust passage.

The second avenue of support for veridicalism is this. The anemia metaphor is apt precisely because of the contrast with (thickly) robust theories. It derives its legitimacy from that contrast. Without that contrast, B-theoretic succession is left a kind of passage that is free from any anemia-related blemish. We don't perceive the becoming present of events, but we do perceive succession, simultaneity, and duration. These latter notions now appear in a different light. There is no sense in which they are static notions, not just because time is included in the block universe but because thereby time's passing is too, 
in a fully adequate sense. The negation of premise (1), and thus veridicalism, gains further plausibility from this. The deflationary view makes it easier to believe that all temporal experience presents us with is succession, simultaneity, and duration.

On this development of the veridicalist's story, there isn't even a cognitive illusion (involving a false belief) colouring our temporal EXPERIENCE. At most, there is an unhelpful cognitive habit.

Of course, all this depends on a good case for the deflationary view. But as mentioned, the preceding sections stand on their own: even when taking the debate at face-value, Btheorists need not agree with premise (1) of the argument from experience.

\section{Conclusion}

The role of temporal experience (and temporal EXPERIENCE) in contemporary metaphysics of time is a complex and interesting one. Veridicalism is a viable B-theoretic response to the A-theoretic argument from experience. It gains further support from a deflationary view of the A versus B debate. ${ }^{6}$

\section{References}

Balashov, Y. (2005) "Times of our lives: negotiating the presence of experience", American Philosophical Quarterly 42(4), pp. 295-309.

Baron, S., Cusbert, J., Farr, M., Kon, M. and Miller, K. (2015) “Temporal experience, temporal passage, and the cognitive sciences", Philosophy Compass 10(8), pp. 560-571. 
Butterfield, J. (1984) “Seeing the present”, Mind 93(370), pp. 161-176.

Braddon-Mitchell, D. (2013) “Against the Illusion Theory of Temporal Phenomenology”, Proceedings of the CAPE International Workshops, CAPE Studies in Applied Philosophy and Ethics Series, Vol. 2, T. Sato, S. Sugimoto and T. Sakon (Eds.), Kyoto University, Kyoto, Japan: CAPE Publications, pp. 211-222.

Callender, C. (2008) “The common now”, Philosophical Issues 18(1), pp. 339-361.

Deng, N. (2013a) "Fine's McTaggart, temporal passage, and the A versus B-debate", Ratio, 26(1), pp. 19-34.

Deng, N. (2013b) "On explaining why time seems to pass", Southern journal of philosophy 51(3), pp. 367-382.

Deng, N. (2013c) "Our experience of passage on the B-theory", Erkenntnis 78(4), pp. 713-726.

Dieks, D. (2006) “Becoming, Relativity and Locality”, in D. Dieks (Ed.), The ontology of spacetime, Elsevier, pp. 157-176.

Dorato, M. (2006) “Absolute Becoming, Relational Becoming and the Arrow of Time: Some Non-conventional Remarks on the Relationship Between Physics and Metaphysics", Studies in History and Philosophy of Modern Physics 37, pp. 559-576. Frischhut, A. (2013) "What experience cannot teach us about time", Topoi 1, pp. 1-13. Hoerl, C. (2014a) "Do we (seem to) perceive passage?", Philosophical Explorations 17(2), pp. 188-202.

Hoerl, C. (2014b) "Time and the domain of consciousness", Annals of the New York Academy of Sciences 1326, pp. 90-96.

Kriegel, U. (2015) "Experiencing the Present", Analysis 75, pp. 407-413. 
Leininger, L. (2013) “On Mellor and the future direction of time”, Analysis, 74(1), pp. 19.

Le Poidevin, R. and Mellor, D. H. (1987) "Time, change, and the 'indexical fallacy'”, Mind 96(384), pp. 534-538.

Le Poidevin, R. (2007) The images of time: an essay on temporal representation, Oxford: Oxford University Press.

Mellor, D. H. (1998) Real time II, Routledge.

Mozersky, M. J. (2015) Time, language, and ontology: the world from the B-theoretic perspective, Oxford: Oxford University Press.

Norton, J. D. (2010) “Time Really Passes”, Humana Mente: Journal of Philosophical Studies 13, pp. 23-34.

Oaklander, L. N. (2012) “A-, B-, and R-theories of time: A debate”, in A. Bardon (Ed.), The future of the philosophy of time, London: Routledge, pp. 1-24.

Olson, E. T. (2009) "The passage of time”, in R. Le Poidevin, A. Bardon, A. McGonigal, R. P. Cameron (Eds.), The Routledge companion to metaphysics, Routledge.

Paul L. A. (2010) “Temporal experience”, Journal of Philosophy 107(7), pp. 333-359.

Pooley, O. (2013) "Relativity, the open future, and the passage of time", Proceedings of the Aristotelian Society 113(3pt3), pp. 321-363.

Price, H. (1996) Time's arrow and Archimedes' point: new directions for the physics of time, Oxford: Oxford University Press.

Saunders, S. (2002) "How relativity contradicts presentism", Royal Institute of Philosophy Supplement 50, pp. 277-292. 
Savitt, S. (2002) "On absolute becoming and the myth of passage", Royal Institute of Philosophy Supplement 50, pp. 153-167.

Skow, B. (2015) Objective becoming, Oxford: Oxford University Press.

\section{Further reading}

Bardon, A. (2010) 'Time-awareness and projection in Mellor and Kant', Kant-Studien 101(1), pp. 59-74.

Benovsky, J. (2013) 'From experience to metaphysics: on experience-based intuitions and their role in metaphysics', Noûs 49(3), pp. 684-697.

Callender, C. (forthcoming) What makes time special, Oxford: Oxford University Press.

Dorato, M. (2015) 'Presentism and the experience of time', Topoi 34(1), pp. 265-275.

Forbes, G. (2015) 'Accounting for experiences as of passage: why topology isn't enough', Topoi 34(1), pp. 187-194.

Ismael, J. (2011) 'Temporal experience', in C. Callender (Ed.), The Oxford handbook of philosophy of time, Oxford: Oxford University Press.

Ludlow, P. (2015) 'Tense, the dynamic lexicon, and the flow of time', Topoi 34(1), pp. 137-142.

Prosser, S. (2016) Experiencing time, Oxford: Oxford University Press.

Prosser, S. (2013) 'Passage and perception.’ Noûs 47(1), pp. 69-84.

Prosser, S. (2012) 'Why does time seem to pass?' Philosophy and Phenomenological Research 85(1), pp. 92-116.

Prosser, S. (2007) 'Could we experience the passage of time?' Ratio 20(1), pp. 75-90.

Suhler, C. \& Callender, C. (2012) 'Thank goodness that argument is over: explaining the temporal value asymmetry', Philosophers' Imprint 12(15), pp. 1-16. 


\footnotetext{
${ }^{1}$ See for example Savitt 2002; Dorato 2006; Dieks 2006; Oaklander 2012; Leininger 2013; Deng 2013a; Mozersky 2015.

${ }^{2}$ See for example Saunders 2002; Pooley 2013.

3 The 'as of' locution is meant to signal that the experience in question needn't be veridical, i.e. one can have an experience as of $\mathrm{x}$ without there being any $\mathrm{x}$.

${ }^{4}$ See for example Hoerl 2014a, 2014b; Frischhut 2013; Deng 2013c; Braddon-Mitchell 2013.

${ }^{5}$ One could perhaps read Kriegel as saying this himself, and thus as intending merely to show that veridicalism is a lot less counterintuitive than it's generally taken to be. However, he does present his proposal as a novel response to the argument from experience, distinct from both veridicalism and illusionism. 6 This work was supported (in part) by the Yonsei University Future-Leading Research Initiative of 2017 (2017-22-0108).
} 